УДК 004.75:620.9:336.7

O.I. Konashevych, post-graduate

Pukhov Institute for Modeling in Energy Engineering of NAS of Ukraine

(15, General Naumov St., Kiev, 03164, Ukraine, e-mail: a.konashevich@gmail.com)

\title{
Advantages and Current Issues of Blockchain Use in Microgrids
}

This paper provides the analysis of the blockchain use in microgrids. The analysis is given from the hypothesis that with the help of IT instruments, self-governed decentralized organizations based on blockchain technology will take and perform public functions traditionally performed by central authorities and corporations in order to organize their relations within the microgrids.

Представлен анализ использования технологии blockchain в энергетических микросетях на основе гипотезы о том, что с помощью IT-инструментов самоуправляемые децентрализованные организации будут выполнять публичные функции, традиционно выполняемые центральными органами и компаниями для организации отношений в рамках работы микросетей.

Key words: blockchain, microgrid, e-government, e-democracy, bitcoin, decentralized autonomous organizations, decentralization, peer-to-peer.

The Problem. The blockchain technology [1] has attracted public interest [2] as it provides an effective instrument to satisfy the needs of people to cooperate horizontally with each other in economic and social spheres. Virtual cryptocurrencies [3] are currently enabling successful peer-to-peer interaction of large quantity of people (the average number of transactions per day is about 200,000 [4] with 400,000 [5] average number of unique wallets) without any central or middle-level management, without any mediators or coordination and hierarchy inside the network. These decentralised peer-to-peer structures can be approached as a new paradigm of management that has potential to change traditional forms of governance and management.

Program algorithms operating in such peer-to-peer networks are able to perform the role of executive management, and the blockchain itself provides a secure and reliable instrument for recording transactions in a distributed public computer network and creating variable distributed applications to solve certain tasks of interaction within such networks.

(C) O.I. Konashevych, 2016 
J. Rifkin [6] describes a microgrid like a local energy grid with control capability, which means it can be disconnected from the central grid and operate autonomously. Under the conception of the third industrial revolution of J. Rifkin, the great number of ordinary energy consumers could become producers of electricity using renewable energy of the wind, sun, waves, biomass and so on. Those who produce and consume are usually called "prosumers".

As the length of power lines is the main source of energy loss, microgrids technology is focused on local use of renewable sources, as a result there is no need to transport energy over long distances that reduces losses.

The current issue is finding the most effective model of management of such microgrids: accounting of produced and consumed energy within the large number of prosumers which, as independent players, enter into relationship within the grid; and coordination of such participants in the sense of volume of energy production and consumption (to maintain balance) including cooperation with centralized networks, since such networks are not currently designed for such interaction and tasks.

Currently, the US Department of Energy is spending 55 million US dollars to support eight projects of microgrids [7]. Similar studies are conducted in Europe [8], Japan [9], China [10], Australia [11]. In most cases such projects are looking for and experimenting with their own original solutions in order to find finally the best one.

N. Hatziargyriou, professor of the National Technical University of Athens (Greece), writes about intelligent load controllers managed by microcomputers which are provided to solve the problem of interaction between "agents" (of the network) by negotiation "algorithms" [8]. These "negotiations" solved the issue of automate order generation, production, supply and consumption.

The problems of using the control systems of such smart controllers and smartgrids are also studied by Japanese scientists Sneha Kulkarni and Sunil Sontakke [12].

The author's research has shown that the issues of software and hardware provision of microgrids are not considered in Ukrainian science.

The construction of microgrids is consistent with the declared principles of the European Union [13]. Thus, due to the development of ideas of the third industrial revolution, the European Parliament Declaration on Creating Hydrogen and Green Economy Third Industrial Revolution in Europe Through a Partner-

\footnotetext{
${ }^{1}$ «Pro» means «producer» and it mixes with «consumer» - a man who is both a producer and consumer. The word is known from The Third Wave (1980) written by Alvin Toffler. «Producer + consumer» is used in the context of the forecast of a type of economy where the gap between producer and consumer will be erased. Prosumer is a man who creates things himself (grows food, makes furniture and so on) and can do it for other people.
} 
ship with Regions and Cities, SMEs and Civil Society Organizations that Have Joined [13] was adopted.

It is hypothesized that the blockchain technology is the most effective solution for the task of automated (smart) management of interaction within such microgrids, because the blockchain itself was designed to the distributed cooperation of the large quantity of users in a decentralized manner. As a result, there is no need to maintain centralized authorities/corporations or any other relevant intermediaries to manage such grids.

One of the main issues in designing the microgrid networks is the automation of accounting and managing the production/consumption of electricity since the manual management in a classic centralized approach would cost a lot.

Most effective model of cooperation in microgrids is that prosumers from one source of energy supply surpluses of unconsumed electricity during the peaks of production to prosumers who use other sources of energy in the moment of inactiveness. For example, during the sunny day solar systems supply energy for those whose wind turbines are inactive during windless weather, and wind turbines supply energy at night for prosumers of solar energy. To compensate the variability of renewable energy sources the users can connect to a centralized energy infrastructure. But the most interesting are the methods of market driven mechanisms (price competition) of the overconsumption control in the form of program algorithms in self-governed microgrids.

All the mentioned tasks could be solved by the blockchain technology in automated manner in horizontal cooperation of prosumers. On the one hand, the blockchain technology, designed for accounting data, is often called as accounting book - a ledger, on the other hand it performs the solution of the consensus issue in a peer-to-peer network, particularly by obtaining consistent results in peer-to-peer group without involvement of the third party or transfer of powers to one of the participants.

The technology of P2P-network implemented in the blockchain concept, allows waiving the trusted third party to process data and gives full featured instrument to people to make the peer-to-peer transaction.

Blockchain Conception. The blockchain is the technology which provides chronological records of transactions performed by users of a public network in the database which is cryptographically secured. The copy of such database, which is also called a "ledger" or "cryptoledger", is stored on each node. Nodes can be freely connected to a public network by any user. The right to make each new record of a portion of done transactions (called "block") is gained by one of the connected nodes each time when a node solves the mathematical issue. By this algorithm the unpredictability of the node choice is provided. Therefore it prevents the network from centralization and usurpation of a right to make records. 
Table 1. Blockchain projects and conceptions

\begin{tabular}{|c|c|c|c|c|c|c|c|}
\hline $\mathrm{N}$ & Name & $\begin{array}{c}\text { Date } \\
\text { of Launch }\end{array}$ & Features & $\begin{array}{c}\text { Bitcoin- } \\
\text { based }\end{array}$ & Consensus & $\begin{array}{l}\text { Auxilia- } \\
\text { ry coin }\end{array}$ & $\begin{array}{c}\text { White } \\
\text { Paper \& } \\
\text { Discussions }\end{array}$ \\
\hline 1 & NXT & $\begin{array}{c}\text { November } \\
2013\end{array}$ & $\begin{array}{l}\text { Voting } \\
\text { Smart property \& Asset Ex- } \\
\text { change } \\
\text { Anonymous Payment System, } \\
\text { Decentralized domain name } \\
\text { system (Alias System) } \\
\text { Messenger } \\
\text { Data Storage } \\
\text { Plugin Support (users plugin } \\
\text { allowed) } \\
\text { Monetary System (users can } \\
\text { create own currencies) } \\
\text { Multi-signature and Phased } \\
\text { transactions }\end{array}$ & - & $\begin{array}{l}\text { Proof of } \\
\text { Stake, } \\
\text { Forging }\end{array}$ & $\begin{array}{l}\text { Next } \\
\text { coin } \\
\text { User } \\
\text { Curren- } \\
\text { cies }\end{array}$ & {$[27,28]$} \\
\hline 2 & $\begin{array}{l}\text { Colored } \\
\text { Coins }\end{array}$ & June 2013 & $\begin{array}{l}\text { Smart property \& Asset Ex- } \\
\text { change } \\
\text { Monetary System (users can } \\
\text { create own currencies) } \\
\text { Copyrights } \\
\text { Smart contracts }\end{array}$ & + & $\begin{array}{l}\text { Proof of } \\
\text { Work }\end{array}$ & None & [29] \\
\hline 3 & $\begin{array}{l}\text { Omni } \\
\text { (ex-Mas- } \\
\text { tercoin) }\end{array}$ & July 2013 & $\begin{array}{l}\text { Smart property \& Asset Ex- } \\
\text { change } \\
\text { Mastercoin/bitcoin exchange } \\
\text { Data feeds and simple bet- } \\
\text { ting } \\
\text { Contract-for-difference bets }\end{array}$ & + & $\begin{array}{l}\text { Proof of } \\
\text { Work }\end{array}$ & $\begin{array}{l}\text { Master- } \\
\text { coin } \\
\text { (MSC) } \\
\text { User } \\
\text { Curren- } \\
\text { cies }\end{array}$ & {$[30,31]$} \\
\hline 4 & $\begin{array}{l}\text { Counter- } \\
\text { party }\end{array}$ & $\begin{array}{c}\text { January } \\
2014\end{array}$ & $\begin{array}{l}\text { Asset Exchange } \\
\text { Programmable Smart Con- } \\
\text { tracts (built-in Turing-com- } \\
\text { plete scripting language) } \\
100 \% \text { compatible with } \\
\text { Ethereum scripting } \\
\text { Betting platform and predic- } \\
\text { tion market } \\
\text { Token Controlled Access } \\
\text { (TCA) - access to private fo- } \\
\text { rums, chatrooms, games, } \\
\text { projects or other social media } \\
\text { based on the ownership of } \\
\text { tokens } \\
\text { Proof of Publication - Using } \\
\text { broadcasts, users can publish } \\
\text { timestamped information } \\
\text { onto the bitcoin blockchain } \\
\text { Verifiable Voting through } \\
\text { the use of user-created to- } \\
\text { kens }\end{array}$ & + & $\begin{array}{l}\text { Proof-of- } \\
\text { Burn }\end{array}$ & $\mathrm{XCP}$ & [32-34] \\
\hline
\end{tabular}


Table 1 (continued)

\begin{tabular}{|c|c|c|c|c|c|c|c|}
\hline $\mathrm{N}$ & Name & $\begin{array}{l}\text { Date of } \\
\text { Launch }\end{array}$ & Features & $\begin{array}{c}\text { Bitcoin- } \\
\text { based }\end{array}$ & Consensus & $\begin{array}{l}\text { Auxilia- } \\
\text { ry coin }\end{array}$ & $\begin{array}{l}\text { White Paper } \\
\& \\
\text { Discussions }\end{array}$ \\
\hline 5 & $\begin{array}{l}\text { Ethe- } \\
\text { reum }\end{array}$ & July 2015 & $\begin{array}{l}\text { Programmable Smart Con- } \\
\text { tracts (built-in Turing-com- } \\
\text { plete scripting language) } \\
\text { Monetary System (users can } \\
\text { create own currencies) }\end{array}$ & - & $\begin{array}{l}\text { Proof of } \\
\text { Stake }\end{array}$ & $\begin{array}{l}\text { Ether } \\
\text { User } \\
\text { Curren- } \\
\text { cies }\end{array}$ & {$[35,36]$} \\
\hline 6 & $\begin{array}{c}\text { Dash } \\
\text { (ex- } \\
\text { Darkcoin } \\
\text { and } \\
\text { ex- } \\
\text { XCoin) }\end{array}$ & $\begin{array}{l}\text { January } \\
2014\end{array}$ & $\begin{array}{l}\text { Bitcoin-mixing service to } \\
\text { add privacy to transactions }\end{array}$ & + & $\begin{array}{l}\text { Proof of } \\
\text { Work } \\
(\mathrm{X} 11+ \\
\text { InstantX) }\end{array}$ & None & [37-40] \\
\hline 7 & $\begin{array}{l}\text { Zero- } \\
\text { coin } \\
+ \text { Zero- } \\
\text { cash }\end{array}$ & $\begin{array}{l}\text { December } \\
2015\end{array}$ & $\begin{array}{l}\text { Zerocash is a protocol that } \\
\text { adds anonymity to Bitcoins } \\
\text { and Zerocoin (Moneta) is an } \\
\text { original anonymous } \\
\text { cryptocurrency launched } 18 \\
\text { December } 2015 \text {. } \\
\text { Based on zero-knowledge } \\
\text { proof technology }\end{array}$ & $+1-$ & $\begin{array}{l}\text { Proof of } \\
\text { Work }\end{array}$ & Moneta & {$[41,42]$} \\
\hline 8 & Ripple & 2012 & $\begin{array}{l}\text { Open free infrastructure } \\
\text { technology for interbank } \\
\text { transactions of money, secu- } \\
\text { rities or cryptocurrency }\end{array}$ & - & $\begin{array}{l}\text { Superma- } \\
\text { jority }\end{array}$ & $\begin{array}{l}\text { Ripples } \\
\text { (XRP) }\end{array}$ & [43] \\
\hline 9 & $\begin{array}{l}\text { Maid- } \\
\text { safe }\end{array}$ & $\begin{array}{l}\text { In deve- } \\
\text { lopment }\end{array}$ & $\begin{array}{l}\text { Distributed cloud storage } \\
\text { Distributed applications plat- } \\
\text { form } \\
\text { Distributed internal DNS }\end{array}$ & - & $\begin{array}{l}\text { Proof } \\
\text { of Re- } \\
\text { source }\end{array}$ & Safecoins & {$[44,45]$} \\
\hline
\end{tabular}

The irreversibility of made records in the ledger is achieved by cryptographic means when each block of data is cryptographically signed by node which gained the right to make a record. Each new block includes the hash sum of the previous block, so any attempt to change a certain data meets the necessity to perform computations on breaking cryptographic code the complexity of which increases in the progression with each new block of data, and that is why is called "blockchain"2 [1]. Nodes are free to disconnect at any time but each node would have and maintain its own full copy of the ledger which prevents from data loss. The copy of the ledger stored on each node also provides for illegal substitution of data as other nodes do not verify inappropriate copy of the

${ }^{2}$ Originally written as "block chain" by Satoshi Nakamoto in «Bitcoin: A Peer-to-Peer Electronic Cash System» (2008). 
ledger. A node gets the remuneration in the moment of creating a new block in the form of internal virtual currency, and also it can receive a fee for transactions. This all stimulates the node owners to provide their computing power to a public network.

The inability to amend or delete record in a database allows the blockchain network to fix actions which have legal value.

Blockchain Projects. The following blockchain projects and conceptions were selected for the analysis: Ethereum [14], NXT [15], Maidsafe [16], Colored coins [17], Ripple [18], Omni Layer (Mastercoin) [19], Counterparty [20], Dash [21], Zerocoin [22]. The analysis of features of each project is shown in the Table 1.

To determine the degree of comparability of these objects we took into account that some aspects of the blockchain technology had been evolved, since the term itself first appeared in the Bitcoin White paper [1]. The rapid growth of similar projects showed alternative options of this technology which were not present in the original Bitcoin idea.

The features in common are:

1) peer-to-peer structure as the conception of topology of blockchain network;

2) cryptography as the method of data protection;

3) "chain of blocks" as data store method which provides the chain of blocks of data and copy stored on each node of the network.

The proof-of-work [1] conception originally proposed in the Bitcoin project as the method of data processing, was criticized [23] and replaced in some further cryptocurrencies and blockchain projects as it led to a computing power race and a significant increase of power consumption.

As the result of author's research, seven common properties of the analyzed blockchain projects were distinguished, that is described in Table 2.

The described set of features allows creating decentralized autonomous organization [26], or "decentralized autonomous consensus platform", which is a "virtual entity that interfaces with a cryptoledger and performs a specific, preprogrammed task. In its simplest form it is merely an agent programmed to do a specific task, such as acting as a multisignature wallet that sits on the ledger waiting for outside instructions. In order to modify or fulfill its task, it must receive a certain threshold of digital signatures from keyholders (e.g., voters, shareholders) and perhaps with a $67 \%$ majority, have the right to release the entity's funds and modify its code. It can fulfill the functions of an organization, corporation, or agent by conducting operations such as payroll management, issuance of dividends, stock, or debt, or otherwise executing repetitive, mechanical, quantifiable actions from a cryptoledger" [26]. 
The blockchain technology can be used to create an application for manage relations within the microgrid and will perform the following tasks:

authentication of smart controllers which register data of produced and consumed electricity and transfer it to the blockchain;

each smart controller has its own "wallet"/"address" in the blockchain, which is the open key of a certificate; the private key is the key to access to the wallet;

wallet stores information of produced and consumed energy and shows the current stock of energy;

wallet allows a participant to make peer-to-peer transaction with other participant of the microgrid;

virtual currency provides equivalents of volumes and allows free market prices;

free market in the form of stock exchange allows users to make deals on buying-selling electricity directly with each other;

deals on market are done in the form of self-executed contracts, also known as "smart contracts", which provides automatization on accounting and payments;

those consumers who consume planned volumes of energy reduce their cost on electricity;

and visa versa, those who overconsume the electricity, pay extra money;

connection to central grid and reserve stock allows to cover the loss during an emergency and compensate the variability of renewable energy sources.

These are main features that allows the microgrid to function in a distributed manner in the computer network without need of manual and centralized managing. Each prosumer is an equal participant of a grid and can interact with other participants directly without intermediaries.

Such interaction makes the participant to plan its consumption and to act rationally. If someone requires extra electricity to make some planned works (e.g. repairs), he can buy extra electricity beforehand for reasonable price, but consuming the above-plan energy, when there is no emergency, will lead to extra payments at much higher price.

There are two options: to use one of the known public blockchain networks (Bitcoin, Ethereum, NXT, etc.) or to create own fork of the private network. However, in both cases it is essential to provide interaction within the microgrids, since there is an essential need to prevent the fraud by identifying the objects which produce energy.

Offline producers cannot supply energy to the grid, so identification allows them to create a group in the network which will match to the real scale of the grids and prevent from illegal deals.

So in the ledger which deals with crytoassest someone should perform a role of a registrar, who confirms the owner or the crypto asset. The state traditionally 
Table 2. Common properties of the blockchain technology

\begin{tabular}{|c|c|c|}
\hline $\mathrm{N}$ & Property & Description \\
\hline 1 & Self-organized & $\begin{array}{l}\text { There are no central authorities, shareholders or other equiva- } \\
\text { lent persons who have external privileges compared to the } \\
\text { other members of the network. Yet there are some co-founders } \\
\text { who provide vision and conception, development of the soft- } \\
\text { ware, first server(-s) and launch of the network/project. Such } \\
\text { co-founders do not have any privileges and remain ordinary } \\
\text { members. There are no special formal rules or requirements to } \\
\text { join such network and being full feathered member only re- } \\
\text { quires to install the initial software and to connect the com- } \\
\text { puter to the network with such software. }\end{array}$ \\
\hline 2 & Self-governed & $\begin{array}{l}\text { People who join the network as members and users are acting } \\
\text { according to the program algorithms (rules). No one can per- } \\
\text { form its own algorithms. The system algorithms cannot be } \\
\text { changed by any or some of users or members. The possibility } \\
\text { to provide updates to the system can be initially set by such al- } \\
\text { gorithms. The algorithms cannot be affected by the will of any } \\
\text { authority or by any other external rules (such as laws, official } \\
\text { rules) as they are performed as a machine code. }\end{array}$ \\
\hline 3 & Crypto rules & $\begin{array}{l}\text { Some parts the of social rules are transferred to the program al- } \\
\text { gorithms and work as a machine code. So there is no subjec- } \\
\text { tive influence in the system in performing actions. The } \\
\text { freedom of some definite actions is subject as well to algo- } \\
\text { rithms. For instance, any Bitcoin user can send any available } \\
\text { amount of cryptocurrency in his wallet to any other wallet in } \\
\text { the system, but algorithms prevent user from double spending } \\
\text { transactions or doing with this cryptocurrency some beyond } \\
\text { the protocol. 'Crypto' means that data processing are secured } \\
\text { with crypto algorithms. Wright and De Filippi have proposed } \\
\text { term "Lex Cryptographia" to refer to the rules administered } \\
\text { through self-executing smart contracts and decentralized (au- } \\
\text { tonomous) organizations [24]. }\end{array}$ \\
\hline 4 & Open ledger & $\begin{array}{l}\text { The hash sum of each previous blocks is included in each addi- } \\
\text { tional block of data providing sequential chain of blocks of } \\
\text { stored transactions. The chain of records of transactions is a } \\
\text { ledger stored on each computer of the network. The data is } \\
\text { open and the system provides irrevocable records with times- } \\
\text { tamp, which is necessary for legal deeds (transactions). }\end{array}$ \\
\hline 5 & $\begin{array}{l}\text { Public peer-to-peer com- } \\
\text { puter network }\end{array}$ & $\begin{array}{l}\text { The base of the network in which the blockchain system oper- } \\
\text { ates is the participation of an unlimited number of persons } \\
\text { with no qualificative rules of membership. Members of the } \\
\text { network with their computers, called 'nodes', provide their } \\
\text { computing power to make the system work. Program algo- } \\
\text { rithms are performed by computers of such network. Users are } \\
\text { another part of the network. It is not required to provide nodes } \\
\text { for those who want only to use the benefits of the system. }\end{array}$ \\
\hline
\end{tabular}


Table 2 (continued)

\begin{tabular}{|c|c|l|}
\hline $\mathrm{N}$ & \multicolumn{1}{|c|}{ Property } & \multicolumn{1}{c|}{ Description } \\
\hline 6 & $\begin{array}{l}\text { Distributed cooperation } \\
\text { with no intermediaries }\end{array}$ & $\begin{array}{l}\text { The network has no hierarchy, but a horizontal structure, con- } \\
\text { necting peer-to-peer all elements of the network. No members } \\
\text { have the privilege status or extra rights within the network. } \\
\text { Likewise, there are no middlemen, managers or coordinators } \\
\text { who provide the interaction within the system. People make } \\
\text { direct transactions with each other. Nodes get the remunera- } \\
\text { tion in the form of an internal award (cryptocurrency). Users } \\
\text { may be asked to pay fee for work performed by nodes. } \\
\text { The software of the public network is open and based on an } \\
\text { open licenses [25]. }\end{array}$ \\
\hline
\end{tabular}

performs this task as a "player" or delegates it to private parties. Such data is traditionally organized in the form of public registries.

The original blockchain protocols and other blockchains have no mechanisms for identification and authentication of individuals (but still it has reliable mechanism of anonymous authorization). So they do not meet such requirements. Therefore, there is a need to update the protocol to provide identification and authentication by adding an appropriate algorithm. There are two known options:

to provide an original new algorithm of identification into the blockchain protocol. Original in this case means to build some kind of independence of known eID infrastructure;

to associate the blockchain with central public infrastructure of electronic identification, which is performed by trusted third parties known as "Certification Authorities".

In all cases there is a practical task to associate certain blockchain address ("wallet") with a specific person or object like smartcontroller of energy supply.

Private grids which use the blockchain can be self-governed by the set identification rules. A microgrid community can delegate the right for identification to some specific registers or to perform collective identification when users identify each other.

\section{CONCLUSION}

As the foundation stones of decentralized autonomous organizations, the smart property and smart contracts do not need much public regulation and state interference. "Smart" is a private law in the form of program algorithms. It does not need enforcement, since it is performed by computers within the open community networks.

As a result of this analysis, we are faced the problem of identification of a person and identification of an object of ownership. In both cases there are no technologies which can provide identification without the participation of a third 
party. The third "party" means an authoritative party (or parties) which confirms the user's personality and the fact of existence of a thing. Whether it would be performed by state officials or private players, a virtual community would face this issue each time when its interest concerns money, property and collective decision making.

One suggestion here would be to use a current infrastructure of Certified Authorities (CA) which certify digital signatures. This means that the process of person's identification can be performed by a private party who has authorization (from either the state or community) for this task and acts according to official rules and laws.

The microgrid model based on the blockchain is an example of decentralized autonomous organization where the set self-executed rules performed by computers allows us to cooperate without need to trust anyone to delegate powers to control the process. This conception generally corresponds with the idea of horizontal energy.

\section{REFERENCES}

1. Nakamoto, S. (2008), Bitcoin: A peer-to-peer electronic cash system, available at: https:// bitcoin.org/bitcoin.pdf (accessed February 15, 2016).

2. US Senate site (2013), available at: http://www.hsgac.senate.gov/hearings/beyond-silk-road-potential-risks-threats-and-promises-of-virtual-currencies (accessed February 15, 2016).

3. http://mapofcoins.com/ (accessed February 15, 2016)

4. https://blockchain.info/ru/charts/n-transactions (accessed February 15, 2016).

5. https://blockchain.info/ru/charts/n-unique-addresses (accessed February 15, 2016).

6. Rifkin, J. (2011), The Third Industrial Revolution,Palgrave MacMillan, 270 p.

7. Daigneau, E. (2012), Microgrid Technology Faces Its 1st Big Test, available at: http:// www.governing.com/topics/energy-env/gov-microgrid-technology-faces-big-test.html (accessed February 15, 2016).

8. Hatziargyriou, N. (2009), The More Microgrids Project, available at: https://ec.europa.eu/ research/conferences/2009/smart_networks/pdf/microgrids.pdf (accessed February 15, 2016).

9. Microgrid Knowledge, Japan Budgets $\$ 21 \mathrm{M}$ for Microgrids: Report (2015), available at: http://microgridknowledge.com/japan-budgets-21m-for-microgrids-report/(accessed February 15, 2016).

10. Asmus, P. (2013), In China's Hinterland, Microgrids Emerge, available at: https://www. navigantresearch.com/blog/in-chinas-hinterland-microgrids-emerge (accessed February 15, 2016).

11. Microgrid Conference in Austrialia (2015), available at: http://www.microgridconference.com/ (accessed February 15, 2016).

12. Kulkarni, S. and Sontakke, S. (2015), Power system analysis of a microgrid using ETAP, International Journal of Innovative Science and Modern Engineering (IJISME), Vol. 3 Iss. 5, available at: http://ijisme.org/attachments/File/v3i5/E0850043515.pdf (accessed February 15, 2016).

13. European Parliament. Written Declaration Pursuant to Rule 116 of the Rules of Procedure on Establishing a Green Hydrogen Economy and a Third Industrial Revolution in Europe through a Partnership with Committed Regions and Cities, SMEs and Civil Society Organisations of May 14, 2007, available at: http://www.europarl.europa.eu/sides/getDoc. do?pubRef=-//EP//NONSGML+WDECL+P6-DCL-2007-0016+0+DOC+PDF+V0//EN\&l anguage $=\mathrm{EN}$ (accessed February 15, 2016). 
14. https://www.ethereum.org/ (accessed February 15, 2016).

15. http://nxt.org/(accessed February 15, 2016).

16. http://maidsafe.net/ (accessed February 15, 2016).

17. http://coloredcoins.org/ (accessed February 15, 2016).

18. https://ripple.com/ (accessed February 15, 2016).

19. http://www.omnilayer.org/ (accessed February 15, 2016).

20. http://counterparty.io/ (accessed February 15, 2016).

21. https://www.dash.org/ (accessed February 15, 2016).

22. http://zerocoin.org/ (accessed February 15, 2016).

23. Cawrey, D. (2015), Inside Butterfly Labs: The ASIC bitcoin mining arms race, available at: $\mathrm{http}: / /$ www.coindesk.com/inside-butterfly-labs-the-asic-bitcoin-mining-arms-race/ (accessed February 15, 2016).

24. Wright, A. and Primavera, De F. (2015), Decentralized blockchain technology and the rise of lex Cryptographia, available at: http://papers.ssrn.com/sol3/papers.cfm?abstract_id= 2580664 (accessed February 15, 2016).

25. https://en.wikipedia.org/wiki/Open-source_license

26. Swanson, T. (2014), Great chain of numbers: A guide to smart contracts, smart property and trustless asset management, available at: http://www.ofnumbers.com/the-guide/ (accessed February 15, 2016).

27. https://bitcointalk.org/index.php?topic=345619.0 (accessed February 15, 2016).

28. https://nxtforum.org/ (accessed February 15, 2016).

29. https://bitcoil.co.il/BitcoinX.pdf (accessed February 15, 2016).

30. https://github.com/OmniLayer/spec (accessed February 15, 2016).

31. https://bitcointalk.org/index.php?topic=265488.0 (accessed February 15, 2016).

32. http://counterparty.io/docs/counterparty_features/ (accessed February 15, 2016).

33. https://bitcointalk.org/index.php?topic=395761.0 (accessed February 15, 2016).

34. https://counterpartytalk.org/ (accessed February 15, 2016).

35. https://github.com/ethereum/wiki/wiki/White-Paper (accessed February 15, 2016).

36. http://gavwood.com/Paper.pdf (accessed February 15, 2016).

37. https://dashpay.atlassian.net/wiki/display/DOC/Official+Documentation (accessed February 15,2016$)$.

38. https://bitcointalk.org/index.php?topic=421615.0 (accessed February 15, 2016).

39. https://www.reddit.com/r/dashpay (accessed February 15, 2016).

40. https://dashtalk.org/ (accessed February 15, 2016).

41. http://zerocash-project.org/media/pdf/zerocash-oakland2014.pdf (accessed February 15, 2016).

42. http://spar.isi.jhu.edu/ mgreen/ZerocoinOakland.pdf (accessed February 15, 2016).

43. https://ripple.com/technology/ (accessed February 15, 2016).

44. http://systemdocs.maidsafe.net/content/en/index.html (accessed February 15, 2016).

45. https://forum.safenetwork.io/ (accessed February 15, 2016).

Received 15.02.16;

After revision 23.02.16

KONASHEVYCH Oleksii Ihorovych is a post-graduate student of the Pukhov Institute for Modeling in Energy Engineering of NAS of Ukraine; graduated from the National Aviation University in 2005. In 2011 he graduated from Kyiv National Trade and Economic University, Advanced Training Institute. The field of research: Blockchain technology. 
